\title{
Analisis Proyeksi Jadwal Dan Biaya Akhir Dengan Konsep Nilai Hasil Pada Proyek Konstruksi
}

\author{
Silvia Yulita RATIH ${ }^{1}$ Dody IRNAWAN ${ }^{2 *}$ \\ ${ }^{1}$ Dosen Program Studi Teknik Sipil Universitas Surakarta, email: vierahayu1125@gmail.com \\ ${ }^{2}$ Dosen Program Studi Arsitektur Universitas Surakarta, email: dodyirnawan@gmail.com
}

Sejarah artikel

Diserahkan: 11 Agustus 2020

Dalam bentuk revisi: 14 September 2020
Diterima: $\quad 16$ September 2020

Tersedia online: $\quad 30$ September 2020

\begin{abstract}
Planning schedules and costs of a construction project that are structured so that the implementation runs smoothly. Controlling the schedule and costs of always carrying out the project does not occur deviation. The method that can be used in terms of cost and time and can show activity performance is the Earned Value Concept Method. By using the yield value concept method, it can be developed to make estimates or project project projections in the future which is a very useful input for managers. the project is bigger than planned. When the project was reviewed, the costs incurred were Rp10.565.790.975, - from what should have been only Rp9.563.051.476, - The estimated time required to complete the project or the Estimated At Completion Date (ECD) is 35 weeks and the estimated cost required to complete the Estimate At Completion (EAC) project is Rp41.645.151.595, - which is bigger than the planned budget of Rp37.689.873.000.00
\end{abstract}

Keywords: result value concept, schedule control, cost control

\begin{abstract}
Abstrak
Perencanaan jadwal dan biaya pada proyek konstruksi disusun agar dalam pelaksanaan berjalan dengan lancar. Pengendalian jadwal dan biaya senantiasa dilakukan supaya proyek tidak terjadi penyimpangan. Metode untuk pengendalian biaya dan waktu sekaligus memperlihatkan prestasi kegiatan digunakan Metode Konsep Nilai Hasil (Earned Value Concept). Dengan menggunakan metode konsep nilai hasil maka dapat dikembangkan untuk membuat perkiraan atau proyeksi keadaan proyek pada masa depan yang merupakan masukan yang sangat berguna bagi pengelola hingga minggu ke-10 Schedule Varians hasilnya positif artinya proyek berjalan lebih cepat dari rencana dan Cost Varians hasilnya negatif artinya biaya proyek lebih besar dari rencana. Pada saat proyek ditinjau, biaya yang digunakan adalah Rp10.565.790.975,- dari yang seharusnya hanya Rp9.563.051.476,-. Hasil perkiraan estimasi waktu untuk penyelesaian proyek atau Estimated At Completion Date (ECD) adalah 35 minggu dan perkiraan kebutuhan biaya untuk menyelesaikan proyek atau Estimate At Completion (EAC) sebesar Rp41.645.151.595,- dibandingkan anggaran rencana hanya sebesar Rp37.689.873.000,00.
\end{abstract}

Kata kunci: nilai hasil, proyeksi jadwal dan biaya

\section{Pendahuluan}

Perencanaan dan pengendalian biaya dan waktu adalah bagian dari suatu manajemen proyek konstruksi secara keseluruhan. Prestasi proyek dapat dinilai dari kualitas, biaya dan waktu. Hal ini jarang terjadi mengingat pelaksanaan proyek biasanya akan mengalami keterlambatan

* penulis koresponden 
atau percepatan dan juga mengalami keuntungan atau kerugian (Pujihastuti, 2012). Pengukuran secara menerus harus dilakukan baik untuk biaya/dana yang telah dikeluarkan maupun waktu yang digunakan dalam menyelesaikan suatu pekerjaan. Adanya temuan biaya dan waktu yang menyimpang secara signifikan merupakan indikasi sebuah pengelolaan proyek yang tidak baik. Adanya indikator prestasi proyek dari segi biaya dan waktu ini memungkinkan tindakan pencegahan agar proyek berjalan sesuai dengan rencana.(Nono et al., 2019)

Pengendalian biaya dan waktu serta penyajian prestasi kegiatan (Performance) salah satunya dapat dilakukan dengan Metode Konsep Nilai Hasil (Earned Value Concept). Dalam metode ini besarnya biaya dihitung sesuai dengan pekerjaan yang telah dilaksanakan menurut anggaran (Budget Cost of Works Performed). Konsep nilai hasil mengamsusikan kecenderungan yang ada dan terungkap pada saat pelaporan. Metode ini dapat digunakan dan dikembangkan untuk menyusun prediksi atau melakukan proyeksi keadaan proyek di masa akan datang. Proyeksi tersebut dapat menjadi masukan berguna bagi pengelola maupun pemilik proyek, karena dengan demikian mereka memiliki cukup waktu untuk memikirkan cara-cara menghadapi permasalahan di waktu yang akan datang (Nasution \& Syahrizal, 2017)

Tujuan dari penelitian adalah untuk mengetahui apakah pelaksanaan proyek sesuai dengan rencana kerja dan berapa banyak anggaran biaya yang sudah digunakan untuk melaksanakan pekerjaan tersebut serta memperkirakan jadwal dan biaya yang akan diperlukan untuk menyelesaikan proyek sampai akhir. Perhitungan maupun analisis jadwal dan biaya yang dimaksud dapat dilakukan dengan berbagai perangkat lunak seperti Microsoft Project dan Primavera (Pancaningrum, Hartono, \& Sugiyarto, 2018; Pinontoan, Mandagi, \& Mangare, 2015; Widayanti, Hartono, \& Sugiyarto, 2017).

Proyek konstruksi adalah rangkaian kegiatan yang hanya satu kali dilaksanakan dan umumnya berjangka pendek. Rangkaian kegiatan tersebut termasuk mengolah sumber daya proyek menjadi suatu hasil berupa bangunan. Proses yang terjadi dalam rangkaian kegiatan itu tentunya melibatkan pihak-pihak yang terkait, baik secara langsung maupun tidak langsung (Ervianto, 2004)

Adapun manajemen proyek adalah proses perencanaan, pengorganisasian, dan pengaturan kegiatan-kegiatan dan sumberdaya-sumberdaya untuk mencapai suatu target prestasi tertentu, dengan batasan waktu, sumberdaya dan biaya. Manajemen proyek lebih menekankan penjadwalan dan pengendalian dibandingkan dengan manajemen dan departemen fungsional. Untuk mencapai tujuan yang telah di tentukan secara efektif maka penjadwalan dan pengendalian proyek harus dilakukan dengan seoptimal mungkin (Wowor et al., 2013)

Permasalahan utama yang sering timbul dalam menangani suatu proyek antara lain:

a. Penyelesaian proyek tepat waktu

b. Biaya proyek yang dibutuhkan lebih besar dari rencana

c. Penerapan sumberdaya tidak efektif

\section{Pengendalian pada Proyek Konstruksi}

Pengendalian merupakan usaha yang sistematis untuk menentukan standar yang sesuai sasaran perencanaan, merancang suatu informasi, membandingkan antara yang direncanakan dengan yang riil dikerjakan, dan melakukan analisis untuk antisipasi kemungkinan munculnya ketidaksesuaian antara rencana dan realita pekerjaan. Dalam hal ini, pengendalian juga mencakup keputusan pengambilan langkah yang esensial guna tetap menjaga efektifitas dan efisiensi sumber daya yang digunakan dalam proses mencapai sasaran dan tujuan (Husen, 2009) 
Walaupun sasaran telah ditetapkan, adanya organisasi dan kepemimpinan yang handal serta motivasi kerja yang tinggi namun tanpa pengawasan dan pengendalian maka mustahil proyek terlaksana dengan baik. Pengawasan dan pengendalian pada proyek dilakukan bertujuan untuk monitoring, mengkaji, melakukan perbaikan atas koreksi, serta melakukan pendampingan agar rencana yang telah ditetapkan terlaksana dengan baik. Waktu Pelaksanaan suatu proyek biasanya berlangsung secara cepat, sehingga perlu dilakukan pengawasan dan pengendalian untuk menghindari terjadinya penyimpangan yang sulit untuk diperbaiki. Sistim pengendalian perlu dilengkapi dengan metode yang tepat sehingga dapat segera memberikan petunjuk atau mengungkapkan adanya penyimpangan (varian) (Syafriandi, 2003)

Menurut (Syafriandi, 2003) fungsi pengendalian adalah :

a. Fungsi pemantauan, semua kegiatan proyek yang dipantau dengan baik akan membuat unsur-unsur pelaksana untuk bekerja secara cakap dan jujur.

b. Fungsi manajerial, sistem informasi dan pengendalian yang baik akan mempermudah manajer untuk mengetahui bagian-bagian pekerjaan yang janggal atau memiliki performa yang kurang baik.

\section{Konsep Nilai Hasil}

Pada proyek konstruksi diperlukan suatu upaya pengendalian yang meliputi proses pengukuran, evaluasi, dan membetulkan kinerja proyek. Ada tiga unsur yang perlu untuk pengendalian dan selalu diukur dalam proyek konstruksi, yaitu:

a. Kemajuan proyek (progress) yang dicapai dibandingkan dengan waktu yang ada pada kesepakatan kontrak

b. Pembiayaan dibandingkan dengan rencana anggaran

c. Mutu hasil pekerjaan terhadap spesifikasi teknis

Konsep Nilai Hasil adalah konsep yang menghitung jumlah besar biaya yang menurut anggaran sesuai dengan pekerjaan yang telah dilaksanakan. Perhitungan ini dapat untuk mengetahui hubungan antara apa yang sesungguhnya telah dicapai secara fisik terhadap jumlah anggaran yang telah dikeluarkan (Marhaendra \& Qomariyah, 2013)

Konsep Nilai Hasil adalah metode pengendalian mengukur biaya dan waktu terintegrasi yang dapat diwujudkan oleh penyimpangan. Sedangkan pengendalian sumber daya untuk menentukan standar sesuai dengan tujuan perencanaan, sistem informasi, membandingkan implementasi dengan standar, menganalisis kemungkinan penyimpangan antara implementasi dan standar, kemudian diperlukan tindakan korektif agar sumber daya digunakan secara efektif dan efisien guna mencapai tujuan.

Konsep Nilai Hasil merupakan sebuah metode dimana kinerja biaya dan waktu diukur secara terpadu dengan tujuan agar dapat mendeteksi apabila ada penyimpangan. Pengendalian dijabarkan sebagai usaha yang sistematis untuk menentukan standar yang sesuai sasaran perencanaan, merancang suatu informasi, membandingkan antara yang direncanakan dengan yang riil dikerjakan, dan melakukan analisis untuk antisipasi kemungkinan munculnya ketidaksesuaian antara rencana dan realita pekerjaan. Selanjutnya, dilakukan pengambilan tindakan penanganan yang diperlukan untuk menjaga efektifitas dan efisiensi dalam rangka mencapai tujuan (Soeharto, 1999)

Besarnya biaya di akhir proyek (Estimasi At Completion) dan juga estimasi waktu selesainya sebuah proyek . (Estimate Completion Date) dapat lebih mudah dilakukan jika dibuat estimasi biaya atau waktu penyelesaian yang didasarkan atas indicator yang didapatkan saat pelaporan. Prakiraan biaya atau jadwal berguna memberikan peringatan awal mengenai halhal yang akan terjadi pada masa mendatang, bila kecenderungan yang ada pada saat pelaporan tidak mengalami perubahan pekerjaan tersisa dianggap kinerjanya tetap (Nono et al., 2019) 
Ada tiga komponen dasar yang menjadi acuan dalam menganalisa kinerja dari proyek berdasarkan konsep Earned Value yaitu :

- ACWP (Actual Cost of Work Performance), yaitu jumlah biaya yang sesungguhnya terpakai untuk kegiatan dalam kurun waktu tertentu.

$\mathrm{ACWP}=$ biaya langsung + biaya tak langsung.

- BCWP (Budgeted Cost of Work Performance), yaitu jumlah anggaran senilai untuk kegiatan yang telah terlaksana.

$\mathrm{BCWP}=\%$ bobot aktual $\mathrm{x}$ anggaran

- BCWS (Budgeted Cost of Work Scheduled), yaitu anggaran yang direncanakan untuk kegiatan yang dilaksanakan.

$\mathrm{BCWS}=\%$ bobot rencana $\mathrm{x}$ anggaran

Sedangkan Metode Analisis Varians adalah metode untuk mengendalikan jadwal dan biaya suatu kegiatan proyek kosntruksi. Imjdentifikasi dilakukan dengan membandingkan jumlah biaya sesungguhnya dikeluarkan terhadap anggaran.

- Perbedaan Jadwal (Schedule Variance),

$$
\mathrm{SV}=\mathrm{BCWP}-\mathrm{BCWS}
$$

- Perbedaan Biaya (Cost Variance),

$$
\mathrm{CV}=\mathrm{BCWP}-\mathrm{ACWP}
$$

Rangkuman analisis nilai varian seperti pada Tabel 1 berikut ini.

\begin{tabular}{|c|c|c|}
\hline $\begin{array}{l}\text { Schedule } \\
\text { Varians }\end{array}$ & Cost Varians & Keterangan \\
\hline Positif & Positif & $\begin{array}{l}\text { Proyek berjalan lebih cepat dan biaya proyek lebih kecil dari yang } \\
\text { direncanakan }\end{array}$ \\
\hline Positif & Negatif & $\begin{array}{l}\text { Proyek berjalan lebih cepat dan biaya proyek lebih besar dari yang } \\
\text { direncanakan }\end{array}$ \\
\hline Negatif & Positif & $\begin{array}{l}\text { Proyek berjalan lebih lambat dan biaya proyek lebih kecil dari yang } \\
\text { direncanakan }\end{array}$ \\
\hline Negatif & Negatif & $\begin{array}{l}\text { Proyek berjalan lebih lambat dan biaya proyek lebih besar dari yang } \\
\text { direncanakan }\end{array}$ \\
\hline Nol & Nol & $\begin{array}{l}\text { Proyek tepat waktu dan proyek berjalan sesuai dengan biaya yang } \\
\text { direncanakan }\end{array}$ \\
\hline Nol & Positif & Proyek tepat waktu dan biaya proyekkecilbesardari yang direncanakan \\
\hline Nol & Negatif & Proyek tepat waktu dan biaya proyek lebih besardari yang direncanakan \\
\hline Positif & Nol & $\begin{array}{l}\text { Proyek berjalan lebih cepat dan proyek berjalan sesuai dengan biaya yang } \\
\text { direncanaka }\end{array}$ \\
\hline Negatif & Nol & $\begin{array}{l}\text { Proyek berjalan lebih lambat dan proyek berjalan sesuai dengan biaya yang } \\
\text { direncanaka }\end{array}$ \\
\hline
\end{tabular}

Tabel 1. Analisis nilai varians

\section{Indeks Kinerja Jadwal dan Biaya}

Indeks kinerja dihitung untuk mengetahui efisiensi penggunaan sumberdana. Adapun rumus - rumusnya yaitu :

a. Indeks Kinerja Jadwal (Schedule Performance Index)

$\mathrm{SPI}=\mathrm{BCWP} / \mathrm{BCWS}$

b. Indeks Kinerja Biaya (Cost Performance Index)

$\mathrm{CPI}=\mathrm{BCWP} / \mathrm{ACWP}$

Nilai Indeks Prestasi Jadwal dan Biaya dapat dilihat seperti pada Tabel 2. 
Tabel 2. Indeks prestasi jadwal dan biaya

\begin{tabular}{|l|l|l|}
\hline $\boldsymbol{S P I}$ & $\boldsymbol{C P I}$ & \multicolumn{1}{c|}{ Keterangan } \\
\hline$>1$ & $>1$ & Proyek berjalan lebih cepat dan biaya proyek lebih kecil dari yang direncanakan \\
\hline$>1$ & $<1$ & Proyek berjalan lebih cepat dan biaya proyek lebih besardari yang direncanakan \\
\hline$<1$ & $>1$ & Proyek berjalan lebih lambat dan biaya proyek lebih kecil dari yang direncanakan \\
\hline$<1$ & $<1$ & Proyek berjalan lebih lambat dan biaya proyek lebih besar dari yang direncanakan \\
\hline 1 & 1 & Proyek tepat waktu dan proyek berjalan sesuai dengan biaya yang direncanakan \\
\hline 1 & $>1$ & Proyek tepat waktu dan biaya proyekkecilbesardari yang direncanakan \\
\hline 1 & $<1$ & Proyek tepat waktu dan biaya proyek lebih besardari yang direncanakan \\
\hline$>1$ & 1 & Proyek berjalan lebih cepat dan proyek berjalan sesuai dengan biaya yang direncanakan \\
\hline$<1$ & 1 & Proyek berjalan lebih lambat dan proyek berjalan sesuai dengan biaya yang direncanakan \\
\hline
\end{tabular}

\section{Proyeksi Jadwal dan Biaya Akhir}

Untuk memperkirakan jadwal dan biaya yang akan diperlukan untuk menyelesaikan proyek dapat dilakukan dengan menganalisa indikator yang telah diperoleh saat pelaporan. Yaitu dengan menghitung:

a. Perkiraan untuk menyelesaikan kegiatan tersisa (Estimate To Complete the Project).

$\mathrm{ETC}=(\mathrm{BAC}-\mathrm{BCWP}) / \mathrm{CPI}$

b. Jumlah biaya keseluruhan (Estimate At Completion) adalah perkiraan biaya yang akan dikeluarkan.

$\mathrm{EAC}=\mathrm{ACWP}+\mathrm{ETC}$

c. Perkiraan Waktu / Estimated At Completion Date (ECD) adalah perkiraan waktu yang dibutuhkan untuk penyelesaian proyek.

$\mathrm{ECD}=($ Sisa Waktu/SPI $)+$ Waktu yang telah dilalui

\section{Metode Penelitian}

Penelitian ini bersifat kuantitatif yaitu jenis penelitian yang memiliki sifat terstruktur dan sistematis, dan juga spesifik, selain itu memiliki perencaan yang baik dari awal hingga akhir untuk mendapatkan suatu. Data yang digunakan adalah data primer dan data sekunder. Data primer berupa Rencana Anggaran Biaya dan bobot kemajuan pekerjaan. Data sekunder diperoleh dari jurnal serta publikasi lainnya yang memuat informasi yang mendukung penelitian ini Objek penelitian adalah proyek Rumah Sakit Umum Muhammadiyah Ponorogo yang berada di lokasi kabupaten Ponorogo dengan anggaran biaya sebesar Rp37.689.873.000,- dengan lama pekerjaan adalah 280 hari.

\section{Analisis dan Pembahasan}

Berikut ini dilakukan analisis untuk memperoleh nilai BCWS perminggu. Nilai ini didapatkan berdasarkan bobot mingguan dalam Time Schedule anggaran seperti pada Tabel 3.

Tabel 3. Perhitungan BCWS

\begin{tabular}{|c|c|c|c|c|}
\hline Minggu ke & BAC & Bobot Rencana (\%) & BCWS (Rp) & BCWS Kumulatif (Rp) \\
\hline 1 & 37.689 .873 .000 & 0,189 & 71.233 .860 & 71.233 .860 \\
\hline 2 & 37.689 .873 .000 & 0,378 & 142.467 .720 & 213.701 .580 \\
\hline 3 & 37.689 .873 .000 & 0,567 & 213.701 .580 & 427.403 .160 \\
\hline 4 & 37.689 .873 .000 & 1,102 & 415.342 .400 & 842.745 .560 \\
\hline 5 & 37.689 .873 .000 & 1,636 & 616.606 .322 & 1.459 .351 .883 \\
\hline 6 & 37.689 .873 .000 & 2,171 & 818.247 .143 & 2.277 .599 .025 \\
\hline 7 & 37.689 .873 .000 & 2,705 & 1.019 .511 .065 & 3.297 .110 .090 \\
\hline 8 & 37.689 .873 .000 & 3,240 & 1.221 .151 .885 & 4.518 .261 .975 \\
\hline 9 & 37.689 .873 .000 & 3,774 & 1.422 .415 .807 & 5.940 .677 .782 \\
\hline 10 & 37.689 .873 .000 & 5,241 & 1.975 .326 .244 & 7.916 .004 .026 \\
\hline
\end{tabular}

Berikut ini dilakukan analisis untuk memperoleh nilai BCWP perminggu. Nilai ini didapatkan berdasarkan pelaksanaan kemajuan pekerjaan atau laporan mingguan proyek seperti pada Tabel 4. 
JURNAL REKAYASA KONSTRUKSI MEKANIKA SIPIL (JRKMS)

Vol. 03 No. 02 September 2020

p-ISSN 2614-5707 e-ISSN 2715-1581

Tabel 4. Perhitungan BCWP

\begin{tabular}{|c|c|c|c|c|}
\hline Minggu ke & BAC & Bobot Rencana (\%) & BCWP (Rp) & BCWP Kumulatif (Rp) \\
\hline 1 & 37.689 .873 .000 & 0,101 & 38.066 .772 & 38.066 .772 \\
\hline 2 & 37.689 .873 .000 & 0,267 & 100.631 .961 & 138.698 .733 \\
\hline 3 & 37.689 .873 .000 & 1,037 & 390.843 .983 & 529.542 .716 \\
\hline 4 & 37.689 .873 .000 & 1,371 & 516.728 .159 & 1.046 .270 .874 \\
\hline 5 & 37.689 .873 .000 & 1,938 & 730.429 .739 & 1.776 .700 .613 \\
\hline 6 & 37.689 .873 .000 & 2,900 & 1.093 .006 .317 & 2.869 .706 .930 \\
\hline 7 & 37.689 .873 .000 & 3,700 & 1.394 .525 .301 & 4.264 .232 .231 \\
\hline 8 & 37.689 .873 .000 & 4,659 & 1.755 .971 .183 & 6.020 .203 .414 \\
\hline 9 & 37.689 .873 .000 & 4,691 & 1.768 .031 .942 & 7.788 .235 .357 \\
\hline 10 & 37.689 .873 .000 & 4,709 & 1.774 .816 .120 & 9.563 .051 .476 \\
\hline
\end{tabular}

ACWP didapat dari penjumlahan biaya langsung, biaya tak langsung dan pajak. Biaya tak langsung didapat dari total biaya tak langsung dibagi jumlah minggu yang ada. Pajak ditambahkan pada minggu ke 10. Perhitungan ACWP seperti pada Tabel 5.

Tabel 5. Perhitungan ACWP

\begin{tabular}{|c|r|r|c|c|c|}
\hline $\begin{array}{c}\text { Minggu } \\
\text { ke }\end{array}$ & $\begin{array}{c}\text { Biaya Langsung } \\
(\text { Rp) }\end{array}$ & $\begin{array}{c}\text { Biaya Tak } \\
\text { Langsung (Rp) }\end{array}$ & ACWP (Rp) & $\begin{array}{c}\text { ACWP Kumulatif } \\
\text { (Rp) }\end{array}$ & Pajak (Rp) \\
\hline 1 & 10.031 .400 & 28.035 .322 & 38.066 .722 & 38.066 .722 & \\
\hline 2 & 63.551 .069 & 28.035 .322 & 91.586 .391 & 129.653 .113 & \\
\hline 3 & 108.025 .120 & 28.035 .322 & 36.060 .442 & 265.713 .555 & \\
\hline 4 & 184.535 .562 & 28.035 .322 & 212.570 .884 & 478.284 .439 & \\
\hline 5 & 338.687 .142 & 28.035 .322 & 366.722 .464 & 845.006 .903 & \\
\hline 6 & 603.646 .949 & 28.035 .322 & 631.682 .271 & 1.476 .689 .174 & \\
\hline 7 & 1.071 .378 .273 & 28.035 .322 & 1.099 .413 .595 & 2.576 .102 .769 & \\
\hline 8 & 1.357 .067 .511 & 28.035 .322 & 1.385 .102 .833 & 3.961 .205 .602 & \\
\hline 9 & 1.436 .970 .042 & 28.035 .322 & 1.465 .005 .364 & 5.426 .210 .966 & \\
\hline 10 & 1.684 .592 .507 & 28.035 .322 & 1.712 .627 .829 & 10.565 .790 .795 & 3.426 .952 .000 \\
\hline
\end{tabular}

Rekapitulasi perhitungan BCWS, BCWP dan ACWP dapat dilihat seperti pada Tabel 6 dan Gambar 1.

Tabel 6. Rekapitulasi perhitungan BCWS Kumulatif, BCWP Kumulatif dan ACWP Kumulatif

\begin{tabular}{|c|r|c|r|}
\hline Minggu ke & BCWS Kumulatif (Rp) & BCWP Kumulatif (Rp) & ACWP Kumulatif (Rp) \\
\hline 1 & 71.233 .860 & 58.066 .772 & 38.066 .722 \\
\hline 2 & 213.701 .580 & 138.698 .733 & 129.653 .113 \\
\hline 3 & 427.403 .160 & 529.542 .716 & 265.713 .555 \\
\hline 4 & 842.745 .560 & 1.046 .270 .874 & 478.254 .439 \\
\hline 5 & 1.459 .351 .883 & 1.776 .700 .613 & 845.006 .903 \\
\hline 6 & 2.277 .599 .025 & 2.869 .706 .930 & 1.476 .689 .174 \\
\hline 7 & 3.297 .110 .090 & 4.264 .232 .230 & 2.576 .102 .769 \\
\hline 8 & 4.518 .261 .975 & 6.070 .203 .414 & 3.966 .205 .602 \\
\hline 9 & 5.940 .677 .782 & 7.788 .235 .351 & 5.426 .210 .966 \\
\hline 10 & 7.916 .004 .026 & 9.563 .051 .476 & 10.565 .790 .795 \\
\hline
\end{tabular}

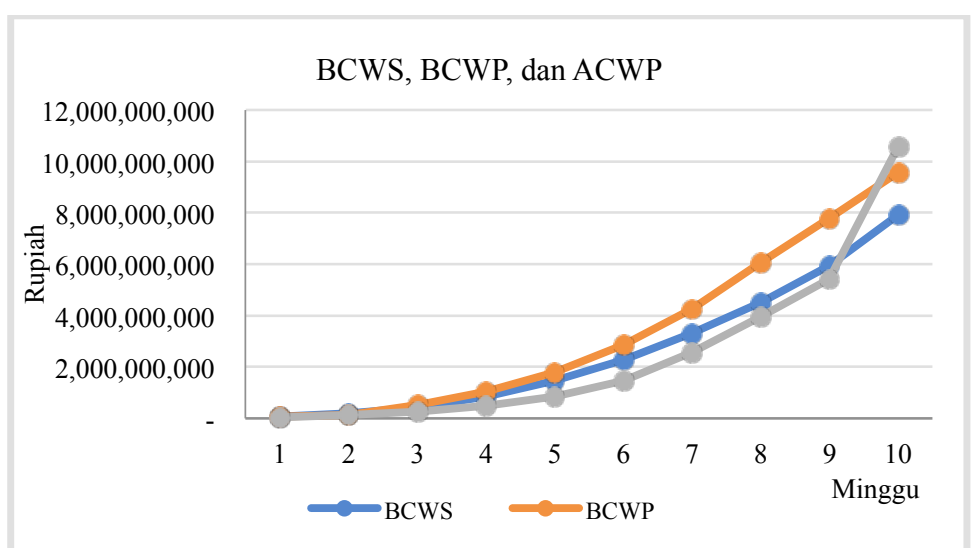

Gambar 1. Kurva BCWS, BCWP dan ACWP 
Grafik pada gambar 1 menunjukkan hubungan antara BCWP, ACWP, dan BCWS. Hubungan ketiga grafik dapat dijelaskan sebagai berikut:

a. Perbandingan grafik BCWP dan BCWS

Grafik diatas menunjukkan bahwa grafik BCWP dari minggu ke-1 sampai minggu ke-10 selalu diatas grafik BCWS. Hal ini menunjukkan bahwa kegiatan yang menurut time schedule sudah seharusnya dikerjakan, sudah dikerjakan.

b. Perbandingan grafik BCWS dan ACWP Grafik menunjukkan bahwa dari minggu ke-1 sampai minggu ke-9 nilai ACWP komulatif lebih kecil dari nilai BCWS kumulatif, yang berarti biaya aktual kumulatif yang dikeluarkan dalam proyek lebih kecil dari biaya kumulatif yang direncanakan. Pada minggu ke-10 nilai ACWP komulatif lebih besar dari nilai BCWS kumulatif artinya biaya aktual kumulatif yang dikeluarkan dalam proyek lebih besar dari biaya kumulatif yang direncanakan.

c. Perbandingan BCWP dan ACWP

Pada minggu ke-1 sampai minggu ke-9 nilai ACWP berada dibawah BCWP yang berarti biaya aktual kumulatif lebih kecil dari biaya yang seharusnya dikeluarkan menurut nilai kontrak. Proyek mengalami keuntungan yang ditunjukkan dengan nilai varians biaya positif. Tetapi pada minggu ke-10 nilai ACWP berada diatas BCWP artinya biaya aktual kumulatif lebih besar dari biaya yang seharusnya dikeluarkan menurut nilai kontrak.

\section{Metode Analisis Varians}

Untuk mendapatkan nilai Perbedaan Jadwal (Schedule Variance) adalah BCWP dikurangi BCWS. Hasil hitungan SV seperti pada Tabel 7.

Tabel 7. Perhitungan SV

\begin{tabular}{|c|c|c|c|c|}
\hline Minggu ke & BCWS Kumulatif (Rp) & BCWP Kumulatif (Rp) & SV (Rp) & SV (\%) \\
\hline 1 & 71.233 .860 & 58.066 .772 & -13.167 .088 & $-0,035$ \\
\hline 2 & 213.701 .580 & 138.698 .733 & -75.002 .847 & $-0,199$ \\
\hline 3 & 427.403 .160 & 529.542 .716 & 102.139 .556 & 0,271 \\
\hline 4 & 842.745 .560 & 1.046 .270 .874 & 203.525 .314 & 0,540 \\
\hline 5 & 1.459 .351 .883 & 1.776 .700 .613 & 317.348 .730 & 0,842 \\
\hline 6 & 2.277 .599 .025 & 2.869 .706 .930 & 592.107 .905 & 1,571 \\
\hline 7 & 3.297 .110 .090 & 4.264 .232 .230 & 967.122 .140 & 2,566 \\
\hline 8 & 4.518 .261 .975 & 6.070 .203 .414 & 1.551 .941 .439 & 4,118 \\
\hline 9 & 5.940 .677 .782 & 7.788 .235 .351 & 1.847 .557 .569 & 4,902 \\
\hline
\end{tabular}

\section{Cost Variance (CV)}

Untuk mendapatkan nilai Perbedaan Biaya (Cost Variance) adalah BCWP dikurangi ACWP Hasil hitungan CV seperti pada Tabel 8.

Tabel 8. Perhitungan CV

\begin{tabular}{|c|c|c|c|c|}
\hline Minggu ke & BCWP Kumulatif (Rp) & ACWP Kumulatif (Rp) & CV (Rp) & CV (\%) \\
\hline 1 & 58.066 .772 & 38.066 .722 & 20.000 .050 & 0,053 \\
\hline 2 & 138.698 .733 & 129.653 .113 & 9.045 .620 & 0,024 \\
\hline 3 & 529.542 .716 & 265.713 .555 & 263.829 .161 & 0,700 \\
\hline 4 & 1.046 .270 .874 & 478.254 .439 & 568.016 .435 & 1,507 \\
\hline 5 & 1.776 .700 .613 & 845.006 .903 & 931.693 .710 & 2,472 \\
\hline 6 & 2.869 .706 .930 & 1.476 .689 .174 & 1.393 .017 .756 & 3,696 \\
\hline 7 & 4.264 .232 .230 & 2.576 .102 .769 & 1.688 .129 .461 & 4,479 \\
\hline 8 & 6.070 .203 .414 & 3.966 .205 .602 & 2.103 .997 .812 & 5,582 \\
\hline 9 & 7.788.235.351 & 5.426 .210 .966 & 2.362 .024 .385 & 6,267 \\
\hline 10 & 9.563 .051 .476 & 10.565 .790 .795 & 1.002 .739 .319 & 2,661 \\
\hline
\end{tabular}

Dari perhitungan dengan Konsep Nilai Hasil untuk varian jadwal (SV) hingga minggu ke 10 hasilnya positif artinya proyek berjalan lebih cepat dari yang direncanakan dan biaya (CV) hasilnya negatif artinya biaya proyek lebih besar dari yang direncanakan. 
JURNAL REKAYASA KONSTRUKSI MEKANIKA SIPIL (JRKMS)

Vol. 03 No. 02 September 2020

p-ISSN 2614-5707 e-ISSN 2715-1581

\section{Analisis Indeks Kinerja Jadwal dan Biaya}

Untuk menghitung Indeks Kinerja Jadwal (Schedule Performance Index) adalah BCWP di bagi dengan BCWS. Hasil hitungan seperti pada Tabel 9.

Tabel 9. Nilai Schedule Performance Index

\begin{tabular}{|c|c|c|c|}
\hline Minggu ke & BCWS Kumulatif (Rp) & BCWP Kumulatif (Rp) & SPI \\
\hline 1 & 71.233 .860 & 58.066 .772 & 0,815 \\
\hline 2 & 213.701 .580 & 138.698 .733 & 0,649 \\
\hline 3 & 427.403 .160 & 529.542 .716 & 1,239 \\
\hline 4 & 842.745 .560 & 1.046 .270 .874 & 1,242 \\
\hline 5 & 1.459 .351 .883 & 1.776 .700 .613 & 1,217 \\
\hline 6 & 2.277 .599 .025 & 2.869 .706 .930 & 1,260 \\
\hline 7 & 3.297 .110 .090 & 4.264 .232 .230 & 1,293 \\
\hline 8 & 4.518 .261 .975 & 6.070 .203 .414 & 1,343 \\
\hline 9 & 5.940 .677 .782 & 7.788 .235 .351 & 1,311 \\
\hline 10 & 7.916 .004 .026 & 9.563 .051 .476 & 1,208 \\
\hline
\end{tabular}

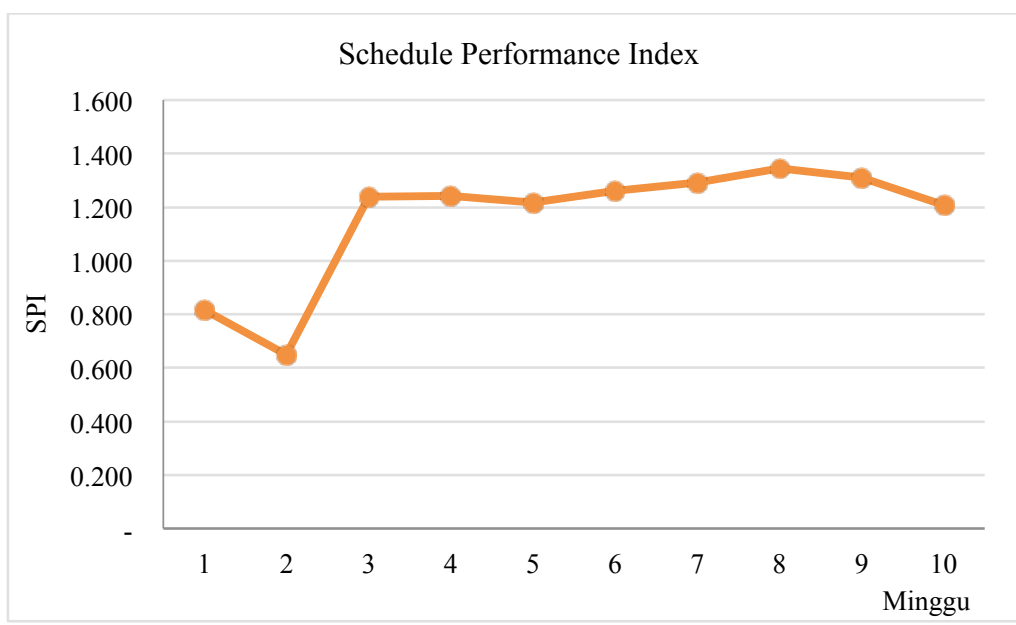

Gambar 2. Schedule performance index

Dari grafik pada gambar 2 terlihat SPI pada minggu ke -1 sampai minggu ke -2 nilainya $<1$ artinya proyek berjalan lebih lambat dari yang direncanakan, baru pada minggu ke-3 samapai minggu ke-10 SPI nilainya $>1$ artinya proyek berjalan lebih cepat dari yang direncanakan.

\section{Indeks Kinerja Biaya}

Untuk menghitung Indeks Kinerja Biaya (Cost Performance Index) adalah BCWP dibagi dengan ACWP. Hasil hitungan seperti pada Tabel 10.

Tabel 10. Nilai Cost Performance Index

\begin{tabular}{|c|c|c|c|}
\hline Minggu ke & BCWP Kumulatif (Rp) & ACWP Kumulatif (Rp) & CPI \\
\hline 1 & 58.066 .772 & 38.066 .722 & 1,525 \\
\hline 2 & 138.698 .733 & 129.653 .113 & 1,070 \\
\hline 3 & 529.542 .716 & 265.713 .555 & 1,993 \\
\hline 4 & 1.046 .270 .874 & 478.254 .439 & 2,188 \\
\hline 5 & 1.776 .700 .613 & 845.006 .903 & 2,103 \\
\hline 6 & 2.869 .706 .930 & 1.476 .689 .174 & 1,943 \\
\hline 7 & 4.264 .232 .230 & 2.576 .102 .769 & 1,655 \\
\hline 8 & 6.070 .203 .414 & 3.966 .205 .602 & 1,530 \\
\hline 9 & 7.788 .235 .351 & 5.426 .210 .966 & 1,435 \\
\hline 10 & 9.563 .051 .476 & 10.565 .790 .795 & 0,905 \\
\hline
\end{tabular}


JURNAL REKAYASA KONSTRUKSI MEKANIKA SIPIL (JRKMS)

Vol. 03 No. 02 September 2020

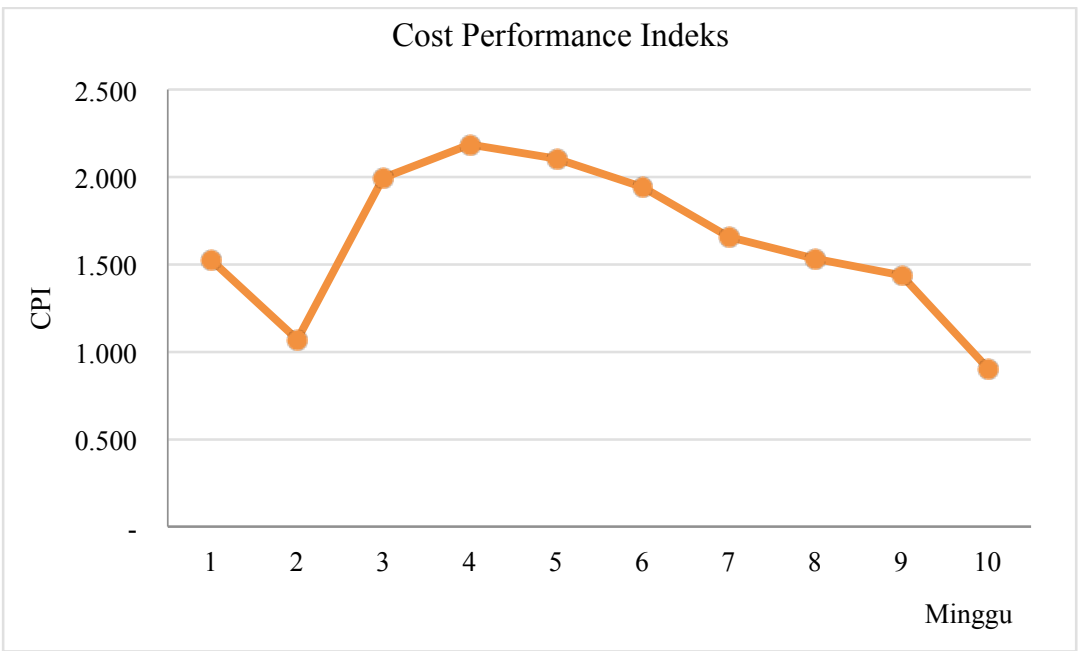

Gambar 3. Kurva Cost Performance Indeks

Dari grafik pada gambar 3 terlihat CPI pada minggu ke -1 sampai minggu ke -9 nilainya $1>$ artinya biaya proyek berjalan lebih kecil dari yang direncanakan, baru pada minggu ke-10 CPI nilainya $<1$ artinya biaya proyek lebih besar dari yang direncanakan.

\section{Analisis Proyeksi Jadwal dan Biaya Akhir}

Jumlah biaya keseluruhan (Estimate At Completion) adalah perkiraan biaya yang akan dikeluarkan. Perhitungan EAC seperti pada Tabel 11 dan Gambar 4.

Tabel 11. Perhitungan Estimation All Completion

\begin{tabular}{|c|c|c|c|c|c|}
\hline Minggu ke & BAC (Rp) & $\begin{array}{c}\text { BCWP Kumulatif } \\
\text { (Rp) }\end{array}$ & $\begin{array}{c}\text { ACWP Kumulatif } \\
(\mathbf{R p})\end{array}$ & CPI & EAC (RP) \\
\hline 1 & 37.689 .873 .000 & 58.066 .772 & 38.066 .722 & 1,525 & $24.714 .660 .969,869$ \\
\hline 2 & 37.689 .873 .000 & 138.698 .733 & 129.653 .113 & 1,07 & $35.224 .208 .502,720$ \\
\hline 3 & 37.689 .873 .000 & 529.542 .716 & 265.713 .555 & 1,993 & $18.911 .137 .681,443$ \\
\hline 4 & 37.689 .873 .000 & 1.046 .270 .874 & 478.254 .439 & 2,188 & $17.225 .787 .403,351$ \\
\hline 5 & 37.689 .873 .000 & 1.776 .700 .613 & 845.006 .903 & 2,103 & $17.922 .121 .685,216$ \\
\hline 6 & 37.689 .873 .000 & 2.869 .706 .930 & 1.476 .689 .174 & 1,943 & $19.397 .515 .766,898$ \\
\hline 7 & 37.689 .873 .000 & 4.264 .232 .230 & 2.576 .102 .769 & 1,655 & $22.772 .864 .563,562$ \\
\hline 8 & 37.689 .873 .000 & 6.070 .203 .414 & 3.966 .205 .602 & 1,53 & $24.632 .656 .311,804$ \\
\hline 9 & 37.689 .873 .000 & 7.788 .235 .351 & 5.426 .210 .966 & 1,435 & $26.263 .589 .118,613$ \\
\hline 10 & 37.689 .873 .000 & 9.563 .051 .476 & 10.565 .790 .795 & 0,905 & $41.645 .151 .595,000$ \\
\hline
\end{tabular}

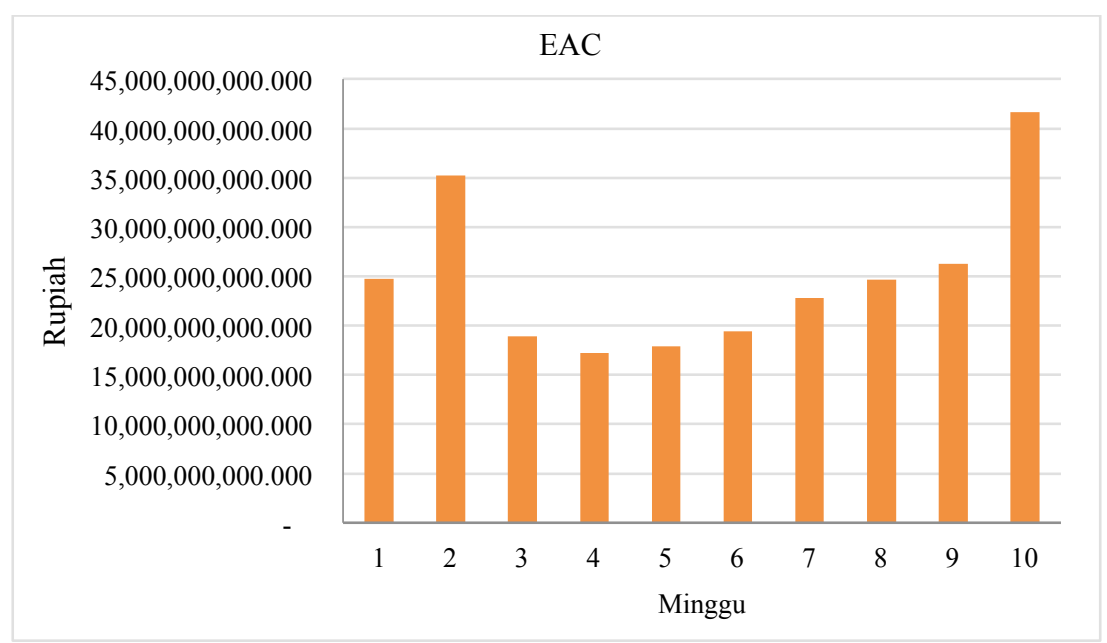

Gambar 4. Histogram Estimation All Completion

Berdasarkan perhitungan dengan EAC didapat perkiraan biaya yang akan dikeluarkan jika kinerja tetap hingga akhir proyek sejumlah Rp41.645.151.595,- lebih besar dari anggaran yang direncanakan sebesar Rp37.689.873.000,-.dan pada saat proyek ditinjau, besarnya biaya 
yang telah dikeluarkan adalah Rp10.565.790.975,-.Sehingga besarnya biaya yang diperlukan untuk penyelesaian proyek yang tersisa adalah Rp30.899.360.620,-.

\section{Estimated At Completion Date (ECD)}

Estimated At Completion Date (ECD) adalah perkiraan waktu yang dibutuhkan untuk penyelesaian proyek.

Waktu yang telah dilalui $\quad=10$ Minggu

Sisa waktu Pelaksanaan $\quad=30$ Minggu

$\mathrm{ECD}=(\mathrm{Sisa} \mathrm{Waktu} / \mathrm{SPI})+$ Waktu yang telah dilalui

$=(30 / 1,208)+10$

$=35$ Minggu

Dari hasil tersebut dapat diketahui jika kinerja proyek tetap proyek akan selesai dalam 35 minggu.

\section{Kesimpulan}

- Hingga minggu ke-10 Schedule Varians hasilnya positif artinya proyek berjalan lebih cepat dari yang direncanakan dan Cost Varians hasilnya negatif artinya biaya proyek lebih besar dari yang direncanakan. Pada saat proyek ditinjau, besarnya biaya yang telah dikeluarkan adalah Rp10.565.790.975.- dari yang seharusnya hanya Rp9.563.051.476.-

- Hasil perkiraan estimasi waktu yang dibutuhkan untuk penyelesaian proyek (ECD) adalah 35 minggu dan perkiraan biaya yang dibutuhkan untuk menyelesaikan proyek (EAC) sebesar Rp41.645.151.595.- yang lebih besar dibandingkan anggaran rencana sebesar Rp37.689.873.000.-

\section{Referensi}

Ervianto, W. I. (2004). Manajemen Proyek Konstruksi (Edisi Revisi). In Andi.

Husen, A. (2009). Manajemen Proyek: Perencanaan, Penjadwalan \& Pengendalian Proyek. Yogyakarta: Andi.

Soeharto, I. (1999). Manajemen Proyek Jilid 1 (Dari Konseptual sampai Operasional). Manajemen Proyek Jilid 1 (Dari Konseptual Sampai Operasional). https://doi.org/10.3938/jkps.60.674

Marhaendra, A., \& Qomariyah, S. (2013). Metode Earned value untuk analisa kinerja biaya dan waktu pelaksanaan pada Pada Proyek Pembangunan Hotel Eastparc Yogyakarta. Jurnal Teknik Sipil Universitas Sebelas Maret.

Nasution, F., \& Syahrizal. (2017). Penerapan Metode Konsep Nilai Hasil (Earned Value Concept) Dalam Pengendalian Proyek (Studi Kasus: Proyek Pembangunan dan Pengandaan Utilitas Gedung Jasindo). Jurnal Teknik Sipil USU, 06(01).

Nono, Y., Pratasis, P. A. K., \& Malingkas, G. (2019). Analisis Metode Nilai Hasil Terhadap Waktu Dan Biaya Pada Proyek Office and Distribution Center, AIRMADIDI, MINAHASA UTARAMANADO. Jurnal Sipil Statik, 7(11), 1465-1467.

Pancaningrum, E., Hartono, W., \& Sugiyarto, S. (2018). Pengendalian Biaya Dan Waktu Dengan Menerapkan Metode Earned Value Analysis (Eva) Menggunakan Software Microsoft Project 2007 (Studi Kasus Di Proyek Pembangunan Hotel Brothers 2 Solo Baru, Sukoharjo). Matriks Teknik Sipil, 6(1).

Pinontoan, M. D. M., Mandagi, R. J. M., \& Mangare, J. B. (2015). Pengendalian Biaya dan Waktu Dengan Metode Analisis Nilai dan Hasil dengan Microsoft Project 2010 (Studi Kasus: Gedung Mantos Tahap III). Jurnal Sipil Statik, 3(12).

Pujihastuti, S. Y. P. M. (2012). Aplikasi Metode Nilai Hasil ( Earned Value Method ) pada Sistem Pengendalian Proyek. Jurnal Ilmiah Semesta Teknika, 15(2), 159-166.

Syafriandi. (2003). Aplikasi Microsoft Project 2000 untuk Penjadwalan Kerja dalam Proyek Teknik Sipil. Jakarta: Dinastindo.

Widayanti, D. A., Hartono, W., \& Sugiyarto, S. (2017). Pengendalian Biaya dan Waktu dengan Menerapkan Metode Earned Value Analysis (EVA) Menggunakan Software PRIMAVERA PROJECT PLANNER P6 (Studi Kasus Proyek Pembangunan Hotel Brothers 2 Solo Baru, Sukoharjo). Matriks Teknik Sipil, 5(4).

Wowor, F. N., Sompie, B. F., Walangitan, D. R. O., Malingkas, G. Y., Teknik, F., Teknik, J., ... Masalah, B. (2013). Aplikasi Microsoft Project Dalam Pengendalian. Jurnal Teknik Sipil. 


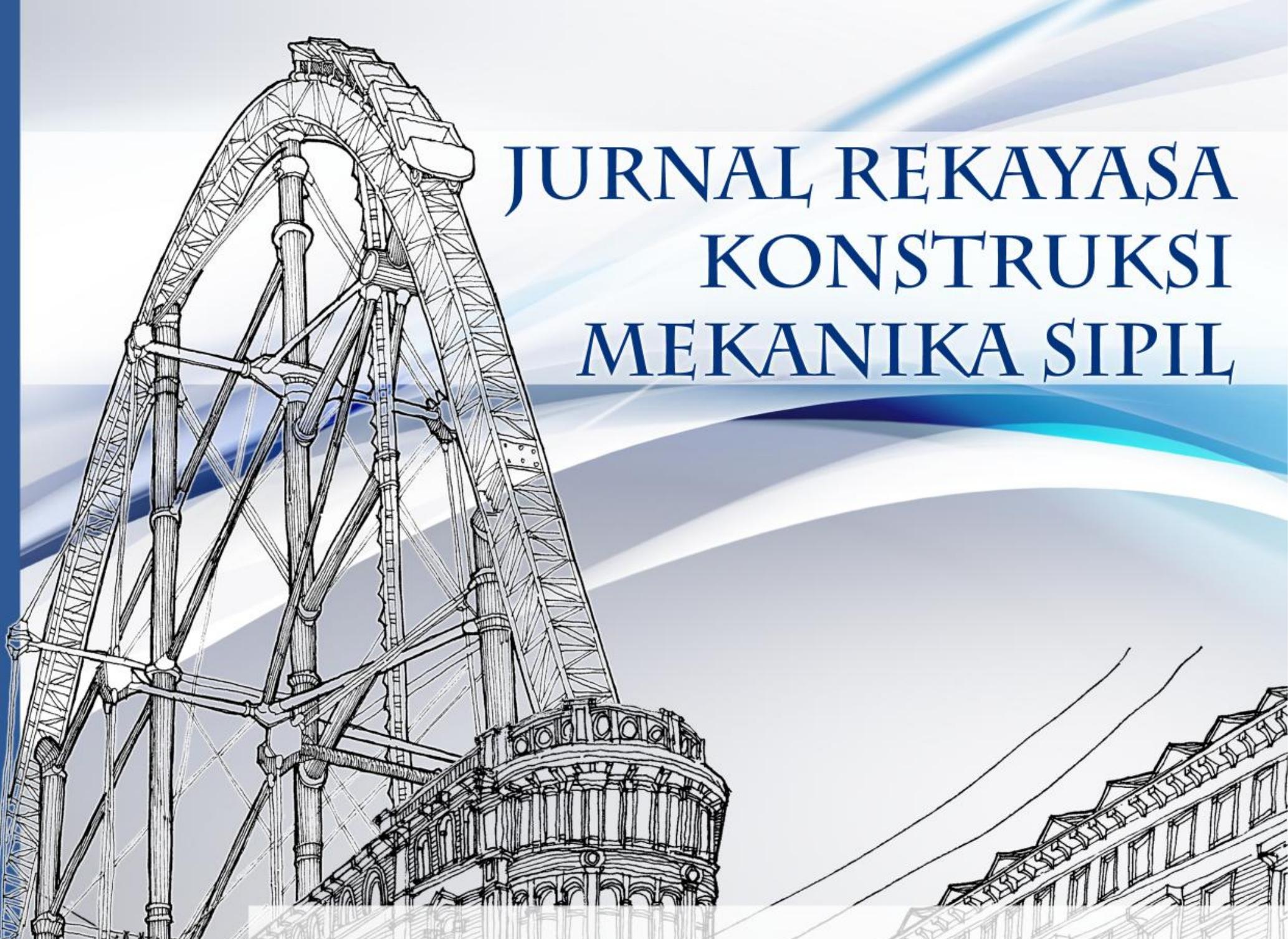

Analisa Perilaku Balok Beton Bertulang dengan Menggunakan Simulasi VecTor2

Sudarno P. TAMPUBOLON

Review Faktor - Faktor Yang Mempengaruhi Karakteristik Kuat Tekan Beton Geopolimer

Putrilyan Ezra PANJAITAN \& Liana HERLINA

Analisis Penerapan Metode Analytic Hierarchy Process (AHP) dalam Penentuan

Daerah Tangkapan Air di Sub DAS Cisadane Hulu

Dina Paramitha Anggraeni HIDAYAT

Dampak Pandemi Covid-19 Terhadap Tingkat Pelayanan Moda Transportasi

Speedboat Tidore-Sofifi

Abdul GAUS, Mufti Amir SULTAN, Iis Hamsir Ayub WAHAB, Abdul Majid ABDULLAH,

\& Nu'man NU'MAN

Analisis Proyeksi Jadwal Dan Biaya Akhir Dengan Konsep Nilai Hasil Pada Proyek Konstruksi

Silvia Yulita RATIH \& Dody IRNAWAN

Fakultas Teknik

Universitas Katolik Santo Thomas

JI. Setia Budi No. 479-F Tanjung Sari, Medan 


\section{Jurnal Rekayasa Konstruksi Mekanika Sipil (JRKMS)}

Jurnal Rekayasa Konstruksi Mekanika Sipil (JRKMS) diterbitkan oleh Fakultas Teknik Universitas Katolik Santo Thomas. JRKMS berisi artikel-artikel ilmiah yang meliputi kajian di bidang Teknik khususnya Teknik Sipil seperti Matematika teknik, Mekanika teknik, Analisis struktur, Konstruksi baja, Konstruksi beton, Konstruksi kayu, Konstruksi gelas, Mekanika tanah, Teknik Pondasi, Hidrologi, Hidrolika, Bangunan air, Manajemen konstruksi, Dinamika Struktur, Earthquake Engineering, Informatika, Ilmu Ukur Tanah, Struktur bangunan sipil, Rekayasa Jalan Raya, serta penelitian-penelitian lain yang terkait dengan bidang-bidang tersebut.

Terbit dalam 2 (dua) kali setahun yaitu pada bulan April dan September

Penasehat :

Prof. Dr. Drs. Sihol Situngkir, MBA. (Rektor UNIKA)

\section{Ketua Penyunting :}

Ir. Oloan Sitohang, M.T. (Universitas Katolik Santo Thomas)

Manajer Jurnal :

Reynaldo, S.T., M.Eng. (Universitas Katolik Santo Thomas)

\section{Anggota Penyunting :}

Medis Sejahtera Surbakti, S.T, M.T., Ph.D. (Universitas Sumatera Utara)

Dr. Janner Simarmata (Universitas Negri Medan)

Ir. Martius Ginting, M.T. (Universitas Katolik Santo Thomas)

Samsuardi Batubara, S.T., M.T. (Universitas Katolik Santo Thomas)

\section{Mitra Bestari :}

Dr.Eng. Aleksander Purba (Universitas Lampung, Indonesia)

Ir. Binsar Silitonga, M.T. (Universitas Katolik Santo Thomas, Indonesia)

Ir. Charles Sitindaon, M.T. (Universitas Katolik Santo Thomas, Indonesia)

Dr. Erica Elice Uy (De La Salle University, Philippines)

Dr. Harijanto Setiawan (Universitas Atma Jaya Yogyakarta, Indonesia)

Dr.Eng. Jeffry Swingly Frans Sumarauw (Universitas Sam Ratulangi, Indonesia)

Prof. Dr-Ing. Johannes Tarigan (Universitas Sumatera Utara, Indonesia)

Linda Prasetyorini (Universitas Brawijaya, Malang, Indonesia)

Dr.Eng. Mia Wimala (Universitas Katolik Parahyangan, Indonesia)

Dr.Eng. Minson Simatupang (Universitas Halu Oleo, Indonesia)

Dr. Mochamad Raditya Pradana (Keppel Marine and Deepwater Technology, Singapura)

Dr. Senot Sangadji (Universitas Sebelas Maret, Indonesia)

Ir. Simon Dertha, M.T. (Universitas Katolik Santo Thomas, Indonesia)

Dr. Thi Nguyên Cao (Tien Giang University, Viet Nam)

\section{Ilustrator Sampul:}

Yulianto, ST., M.Eng

\section{Penerbit \& Alamat Redaksi:}

Fakultas Teknik Universitas Katolik Santo Thomas

J1. Setiabudi No. 479-F Tanjung Sari, Medan 20132

Telp. (061) 8210161 Fax : (061) 8213269

email : unika.sipil@yahoo.com 


\section{Konten}

REKAYASA STRUKTUR

Analisa Perilaku Balok Beton Bertulang dengan Menggunakan Simulasi VecTor2

Sudarno P. TAMPUBOLON

Review Faktor - Faktor Yang Mempengaruhi Karakteristik Kuat Tekan Beton Geopolimer

Putrilyan Ezra PANJAITAN \& Liana HERLINA

TEKNIK SUMBER DAYA AIR

Analisis Penerapan Metode Analytic Hierarchy Process (AHP) dalam

Penentuan Daerah Tangkapan Air di Sub DAS Cisadane Hulu

Dina Paramitha Anggraeni HIDAYAT

\section{REKAYASA TRANSPORTASI}

Dampak Pandemi Covid-19 Terhadap Tingkat Pelayanan Moda

Transportasi Speedboat Tidore-Sofifi

Abdul GAUS, Mufti Amir SULTAN, Iis Hamsir Ayub WAHAB, Abdul Majid

ABDULLAH, \& Nu'man NU'MAN

\section{MANAJEMEN KONSTRUKSI}

Analisis Proyeksi Jadwal Dan Biaya Akhir Dengan Konsep Nilai Hasil Pada

Proyek Konstruksi

Silvia Yulita RATIH \& Dody IRNAWAN hal.

55-64

89-96

97-106 


\section{Pengantar Redaksi}

Puji dan syukur kami sampaikan kepada Tuhan Yang Maha Esa karena atas rahmatNya kami dapat menyelesaikan penerbitan Jurnal Rekayasa Konstruksi Mekanika Sipil (JRKMS) Volume 3 Nomor 2, di bulan September tahun 2020 ini. Jurnal ini fokus pada beragam subbidang dalam Teknik Sipil, yakni Rekayasa Struktur, Rekayasa Geoteknik, Rekayasa Transportasi, Teknik Sumber Daya Air, dan Manajemen Konstruksi. Namun, tidak menutup kesempatan bagi subbidang lainnya yang berkaitan dengan bidang Teknik Sipil. Pada tahun ke-3 terbitnya, JRKMS telah menerima terakreditasi ARJUNA dengan peringkat Sinta S5.

Meski masih dalam kondisi pandemi COVID-19, penelitian tetap harus dijalankan dan produktivitas peneliti di Indonesia masih harus terus berkembang. Dalam edisi ini, terdapat 5 artikel yang terdiri atas dua (2) artikel dalam topik Rekayasa Struktur, satu (1) artikel dalam topik Teknik Sumber Daya Air, satu (1) artikel dalam topik Rekayasa Transportasi, dan satu (1) artikel dalam topik Manajemen Konstruksi. Redaksi/Tim editorial memiliki kerinduan agar semakin banyak peneliti yang menerbitkan karya berkualitasnya di JRKMS untuk mendukung pengembangan wawasan dalam dunia teknik sipil. Apresiasi kami berikan kepada penulis yang tulisannya diterbitkan pada Vol.03 No.02 September 2020 ini karena telah menginvestasikan waktu dalam menuangkan ide dan merespon masukan dari mitra bestari hingga karyanya siap untuk diterbitkan.

Sebagai penutup, yang menjadi harapan tim editorial adalah semoga jurnal ini dapat menjadi media ilmiah yang berguna bagi civitas akademika, dan perkembangan ilmu pengetahuan serta penelitian di bidang ilmu ketekniksipilan di Indonesia. Salam hangat. Salam sehat.

September 2020

Tim Editorial 
JURNAL REKAYASA KONSTRUKSI MEKANIKA SIPIL | Volume 03 | No. 02 | September 2020 | Jurnal IImiahTeknik Sipil Fakultas Teknik Universitas Katolik Santo Thomas ejournal.ust.ac.id/index.php/JRKMS

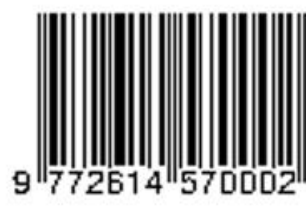

Google A GARUDA ISJDNeo : neliti Donesearch PBase 